\title{
A hipótese da «soldadura» na formação de topônimos indígenas monolexicais de estrutura poliléxica na língua de origem
}

DOI: http://dx.doi.org/10.21165/el.v49i1.2698

\section{Camila André do Nascimento da Silva' \\ Aparecida Negri Isquerdo²}

\section{Resumo}

Este trabalho analisa processos de formação de palavras por composição evidenciados na estrutura morfológica de topônimos pertencentes à mesorregião Sudoeste do Mato Grosso do Sul, com destaque para designativos cujos elementos de origem foram unidos por um processo de soldadura, uma hipótese de trabalho ainda em processo de construção. Trata-se de um recorte de uma pesquisa mais ampla que tem como objeto de estudo a toponímia rural de acidentes físicos de base indígena. Os resultados dos dados discutidos neste trabalho evidenciam um número representativo de unidades lexicais que, em sua configuração sincrônica, são formas simples, mas o estudo etimológico evidencia a presença de uma estrutura composta de base. Dessa forma, discute-se, neste trabalho, o grau de vitalidade de topônimos monolexicais de origem poliléxica e busca-se atestar a hipótese da soldadura como uma característica da toponímia indígena na região estudada. Em termos teóricos, o estudo orienta-se, fundamentalmente, em Rodrigues (1951), Dick (1992) e Gross (1996).

Palavras-chave: soldadura; topônimos monolexicais; topônimos polilexicais; línguas indígenas.

\footnotetext{
1 Universidade Federal do Mato Grosso do Sul (UFMS), Três Lagoas, Mato Grosso do Sul, Brasil camilandreufms@hotmail.com; https://orcid.org/0000-0002-3379-1422

2 Universidade Federal do Mato Grosso do Sul (UFMS), Campo Grande, Mato Grosso do Sul, Brasil; aparecida.isquerdo@gmail.com; https://orcid.org/0000-0003-1129-5775
} 


\section{L'hypothèse de la "soudure» dans la formation de toponymes autochtones monolexicaux à structure polylexique dans la langue d'origine}

\section{Résumé}

Ce travail analyse les processus de formation des mots par composition mis en évidence dans la structure morphologique des toponymes appartenant à la mésorégion sud-ouest du Mato Grosso do Sul, avec un accent sur les désignations dont les éléments d'origine ont été assemblés par un processus de soudure, une hypothèse de travail encore en cours de construction. II s'agit d'une coupure d'une recherche plus large qui a pour objet d'étudier la toponymie rurale d'accidents physiques de base indigène. Les résultats des données discutées dans ce travail mettent en évidence un nombre représentatif d'unités lexicales qui, dans leur configuration synchronique, sont des formes simples, mais l'étude étymologique met en évidence la présence d'une structure composite de base. De cette façon, on discute dans ce travail du degré de vitalité de toponymes monolexicaux d'origine polylexicale et on cherche à attester l'hypothèse de la soudure comme une caractéristique de la toponymie indigène dans la région étudiée. En termes théoriques, l'étude s'oriente essentiellement sur Rodrigues (1951), Dick (1992) et Gross (1996).

Mots-clés: soudure; toponymes monolexicaux; toponymes polylexicaux; langues indigènes.

\section{Introdução}

Conforme Rodrigues (1951), um aspecto do Tupi antigo muito importante, para quem desejar realizar investigações etimológicas, é, sem dúvida, o processo de composição, por tratar-se de uma língua predominantemente incorporante. O autor realiza uma tentativa de sistematização da composição em Tupi e, de início, reitera que "a etimologia, como ciência linguística bem caracterizada, tem seu método e seu rigor muito próprios" (RODRIGUES, 1951, p. 1). Citando Dauzat, o mesmo autor pondera que a etimologia "é sem dúvida o mais sedutor aspecto da linguística, todos os que se apanham com um vocabulário indígena nas mãos entregam-se afoitamente à tarefa de 'fazer etimologia'...". (RODRIGUES, 1951, p. 2).

Pautando-se na tentativa de sistematização de Rodrigues (1951), este artigo tem, também, o objetivo de sistematizar topônimos de origem indígena identificados na toponímia sul-mato-grossense, predominantemente, incorporados à língua portuguesa. Aventa-se a hipótese de que, na formação desses topônimos, há características fronteiriças entre as formas simples e compostas. Dessa forma, este estudo representa uma tentativa de compreensão do processo aglutinador responsável pela mudança de um topônimo polilexical por outro monolexical. Parte-se do ponto de vista de que, em razão 
de mudanças diacrônicas ocorridas na língua, os topônimos originalmente compostos, sincronicamente, evidenciam estrutura simples.

Considera-se como ponto central deste estudo o fato de que, ao projetar a palavra em sua evolução, desde a sua base etimológica, a sua construção, em diferentes fases de desenvolvimento, "confunde" as regras gramaticais da língua. O fator complicador está, exatamente, no fato de palavras compostas serem tomadas como unidades lexicais simples. Nesse contexto, a proposta de Gross (1996) fundamenta este estudo à medida que busca uma distinção diacrônica que leve em conta as diferentes etapas da evolução da unidade lexical e a tese de que os elementos de um composto devem existir como palavras autônomas, para que ele seja solvido com o critério de polilexicalidade.

O fenômeno da composição abrange uma área de contornos imprecisos denominado comumente de formação de palavras. No entanto, não é objetivo deste estudo, pelo menos por ora, propor uma nova concepção da natureza dos compostos em topônimos indígenas, ao contrário, é a partir dos pressupostos de uma definição tradicional de composição que se procura explicar as tendências de formação de palavras em topônimos de base indígena, adotando-se, para tanto, a hipótese da soldadura.

Para este estudo, foi examinada uma amostra de 832 dos 1.815 topônimos indígenas que compõem o corpus da pesquisa mais ampla a que este estudo se vincula ${ }^{3}$, extraídos do Sistema de Dados do Projeto Atlas Toponímico do Mato Grosso do Sul (ATEMS). Em decorrência de mudanças ocorridas na língua, assume-se que muitos desses topônimos, em sua gênese, eram formas compostas que se transformaram, no estágio sincrônico da língua, em nomes com estruturas simples, formados por um processo aqui denominado de soldadura. A partir do recorte de dados analisados, observa-se se determinados topônimos de base indígena se encontram na fronteira entre formas simples e compostas, em razão da ocorrência de um processo aglutinador responsável pela transformação de um topônimo originalmente polilexical em um designativo monolexical.

Estabelece-se, enfim, um ensaio de sistematização morfológica, especificamente, de topônimos que nomeiam acidentes físicos e rurais da Mesorregião Sudoeste do Estado. Para fins de análise, os dados foram divididos em dois blocos: o primeiro, foco central do estudo, analisa topônimos compostos por justaposição e aglutinação, enquanto o segundo, de caráter secundário, considera fenômenos de acomodação fonética e processos de formação de palavras por hibridismo.

3 Projeto de Tese de Doutorado - "A toponímia indígena em Mato Grosso do Sul: um estudo etnolinguístico" -, em curso, na Universidade Federal de Mato Grosso do Sul - Campus de Três Lagoas, sob a orientação da Profa. Dra. Aparecida Negri Isquerdo. 
Este trabalho orienta-se pela proposta de Dick (1990; 1992), no que diz respeito à abordagem de cunho onomástico-toponímico e, no caso específico deste trabalho, busca-se respaldo teórico também na hipótese da soldadura defendida por Gross (1996) e por Mejri (1997), além de pressupostos teóricos de Carone (1986), Kehdi (2007) e Basílio (2013), que fundamentaram o estudo, no que se refere ao exame do processo de formação dos topônimos indígenas. Nesse processo, a consulta a obras lexicográficas de línguas indígenas, tais como, Sampaio (1928, 1987), Tibiriçá $(1985,1989)$ e Bueno (2008), também foi fundamental para subsidiar a descrição etimológica dos topônimos.

A estrutura do artigo engloba os seguintes tópicos: introdução; discussão teórica acerca de pressupostos da Toponímia e do processo de formação de palavras; análise e discussão da estrutura morfológica dos compostos de base indígena identificados no recorte do corpus examinado e, por fim, as considerações finais e as referências.

\section{O conceito de Toponímia}

Os primeiros estudos toponímicos foram realizados no continente europeu e logo destacaram-se e motivaram o interesse de pesquisadores de vários países. De acordo com Dick (1992), a história da Toponímia, como disciplina científica, iniciou-se por volta de 1878, na França, e foi introduzida na École Pratique des Hautes-Études e no Collège de France, por Auguste Longon. Mais tarde, em 1922, Albert Dauzat retomou os estudos onomásticos, interrompidos com a morte de Longon, e publicou a Chronique de Toponymie, com "uma bibliografia crítica, região por região, das fontes e dos trabalhos já publicados". (DICK, 1992, p. 1).

Na perspectiva de Dauzat (1947, p. 7, tradução nossa), "a toponímia, conjugada com a história, indica ou precisa os movimentos antigos dos povos, as migrações, as áreas de colonização, as regiões onde este ou aquele grupo linguístico deixou os seus traços"4. Partindo dessa definição, pode-se considerar que a Toponímia, associada a fatos históricos de um povo, solidifica as impressões deixadas pelos falantes, as características linguísticas do denominador, razão pela qual os nomes de lugares favorecem um estudo etimológico e/ou histórico do item lexical da língua em função de topônimo. Em outras palavras, os estudos toponímicos mostram-se de grande importância para o conhecimento de aspectos linguísticos, histórico-culturais e ideológicos de um povo.

Desde o seu surgimento, a disciplina Toponímia ampliou o seu objeto de estudo e hoje há estudos significativos sobre nomes de lugares em várias partes do mundo. No Brasil, seguindo as orientações de Carlos Drummond, Maria Vicentina de Paula do Amaral Dick

4 No original: "la toponymie, conjuguée avec l'histoire, indique ou précise les mouvements anciens des peuples, les migrations, les aires de colonisation, les régions où tel ou tel groupe linguistique a laissé ses traces. ". 
defende em 1980 a sua tese de doutoramento com o título "A motivação toponímica. Princípios teóricos e modelos taxionômicos" ${ }^{\prime 5}$ que a torna referência no que diz respeito aos estudos toponímicos, tanto pela originalidade como pela relevância de sua pesquisa no Brasil. Inicialmente, Dick (1992, p. II) considerava a Toponímia "como uma disciplina completa acabada, com seu campo de estudos específicos e um método próprio de trabalho". Contudo, a autora também pondera que a Toponímia é uma disciplina aberta e de caráter dinâmico, que vai sendo ampliada à medida que novos espaços são nomeados. Para a toponimista, trata-se de uma disciplina vinculada à Linguística da qual busca seus fundamentos; investiga o léxico como expressão linguístico-social; reflete aspectos culturais e resgata atitudes do homem diante do meio em que vive, por meio do estudo da motivação dos nomes de lugares (DICK, 1992).

Desse modo, entende-se que o homem ocupa papel central nos estudos toponímicos e, nesse sentido, de igual modo, o ambiente no qual ele está inserido e sua maneira de ver o mundo são fatores que interferem na concepção do espaço e, consequentemente, na sua nomeação. Nesse sentido, torna-se importante ressaltar que a Toponímia deve ser entendida como prática social por ser uma atividade desempenhada pelo homem: "a toponímia reflete de perto a vivência do homem, enquanto entidade individual e enquanto membro do grupo que o acolhe" e possui uma "função conservadora das tradições e dos costumes de um povo", considerando-se que por meio do topônimo, "pode-se perceber e sentir a marca de sua inscrição em um contínuo tempo-espacial determinado" (DICK, 1990, p. 19).

Resumindo, pode-se considerar que um estudo toponímico constitui, ao mesmo tempo, um registro científico, um resgate e, até mesmo, uma forma de preservação da cultura e da memória de um povo. Por essa razão, acredita-se, que a Toponímia é capaz de reconstruir estágios do passado humano e isso inclui transformações históricas e alterações linguísticas que foram cristalizadas nos topônimos.

\section{A toponímia indígena: considerações}

Os vestígios das línguas indígenas podem ser identificados com facilidade, quando se examina o léxico da língua portuguesa, especialmente quando se trata da toponímia. Assim, refletir sobre a formação da toponímia brasileira é aceitar a variedade de línguas e culturas que influenciaram o português do Brasil. Para Dick (1992, p. 81), "a formação etno-histórica do Brasil acusa a existência de estratos populacionais diversos como os ameríndios, distribuídos em vários troncos e famílias, os portugueses, os africanos e os de procedência estrangeira" e essa origem heterogênea deixou reflexos na língua,

5 A Tese de Dick foi publicada em 1990 pelo Arquivo do Estado de São Paulo com o título A motivação toponímica e a realidade brasileira. Para este texto foi consultada a publicação em forma de livro. 
nos usos e costumes, nas tradições regionais e, consequentemente, na toponímia. É evidente, contudo, que a maior contribuição em relação à toponímia, é de origem indígena, sobretudo do Tupi.

Segundo Dick (1992, p. 81), o europeu, aqui chegando, encontrou uma nomenclatura indígena básica, que foi incorporada à toponímia do território recém-conquistado, mas "a denominação dos acidentes costeiros, nos primórdios da ocupação, por desconhecimento dessa camada primitiva, foi feita segundo os padrões vigentes na cultura lusitana". A história registra que o processo de nomeação era uma atividade quotidiana para os europeus e, à época da colonização, não foi diferente; os conquistadores tinham essa urgência, pois precisavam demarcar os novos territórios. Assim, topônimos de origem indígena foram apagados, reorganizados e rebatizados, no intuito de conferir à nova terra, neste caso, a brasileira, marcas lusitanas. Deve-se registrar, sobretudo, que a toponímia brasileira de origem indígena apresenta muitos contrastes e incorpora elementos que remontam à cultura material e espiritual de seu povo.

[...] o sistema léxico tupi, envolvendo aspectos da cultura material, deixou uma gama variada de contribuições ao Português do Brasil, que preservou, realmente, nos vocábulos fossilizados, as tipicidades de uma realidade ambiental diversificada ou de múltiplos domínios de experiência. (DICK, 1992, p. 122).

Argumenta ainda a toponimista brasileira que é "nos dados naturais ou físicos, principalmente, que essa toponímia encontra uma definição mais relevante" (DICK, 1992, p. 123). Para a mesma autora, essa propagação dos topônimos indígenas ocorreu não só devido à "mobilidade geográfica ou mesmo sociocultural do grupo, como também à ação religiosa dos missionários e à participação das antigas bandeiras, que difundiram a língua dita então geral, dilatando a área ocupada por esses indígenas" (DICK, 1992, p. 122).

Desse modo, é preciso levar em consideração que a nomenclatura geográfica do território brasileiro é tão mestiça e heterogênea quanto o próprio povo. Em outras palavras, ao lado da abundante toponímia da língua dos colonizadores há um número significativo de topônimos de origem indígena que confirmam o caráter de "fóssil linguístico"6 do nome geográfico e as marcas de sua influência no léxico da língua portuguesa. Sintetizando, é evidente que os vestígios dessa dominação estão presentes nas designações de lugares, e esse fato deve ser levado em consideração quando se examina a toponímia de base indígena e sua relação com a geografia brasileira.

6 Fóssil linguístico é um termo tomado por Dick (1992, p. 20) "ao geógrafo francês Jean Brunes, que o considerava como um fóssil da geografia humana". 
Na sequência, pode causar estranhamento a utilização de literatura francesa sobre o processo de composição tomada como parâmetro para o exame de topônimos indígenas. Essa escolha foi motivada pelos estudos realizados por Gross (1996) e por Mejri (1997), que propõem um fundamento teórico original e complexo para o exame do processo de composição no âmbito da soldadura, aqui considerado um viés teórico que se aplica aos dados em estudo como demonstrado nos tópicos subsequentes.

\section{O processo de composição e a hipótese de «soldadura»}

Para Gross (1996, p. 4, tradução nossa), "por composição, designa-se a formação de uma unidade semântica a partir de elementos suscetíveis de terem, por si próprios, autonomia na língua"7. De fato, o autor defende que os elementos de uma composição devem existir como palavras autônomas, especificadas com o critério de polilexicalidade. Em outros termos, os compostos são obtidos pela fusão de duas ou mais palavras e o critério da autonomia é indispensável para delimitações léxico-gramaticais.

Segundo Gross (1996), a composição é um fenômeno linguístico oposto à derivação. Do ponto de vista quase exclusivamente morfológico, o autor se opõe categoricamente à concepção de morfema livre que, segundo ele, não tem autonomia própria. Além disso, enfatiza que a palavra "composto" é polissêmica na tradição gramatical e está pronta para muitos equívocos. Conforme Gross (1996), as diferentes definições propostas provocam a mudança de foco quanto ao funcionamento real dos elementos linguísticos em favor de preocupações terminológicas e, nomeadamente, o autor recupera e elucida os pontos de vista de Benveniste (1967), Martinet (1965), Pottier (1987) e Darmesteter (1874)8 e, a partir dessas reflexões, apresenta a sua proposta para explicação do fenômeno em pauta.

Assim, Gross (1996) conceitua mot racine (palavra raiz) ou mot simple (palavra simples) como uma unidade não suscetível à decomposição. E qualquer outra palavra é designada pelo linguista como construit (construída). Contudo, entre as palavras construídas, o autor faz duas distinções: palavras dérivés (derivadas) que são formadas por afixos e palavras polylexicaux ou complexes (polilexicais ou complexas), correspondendo a qualquer unidade composta por duas ou mais palavras simples, graficamente soldadas ou não. Na visão

7 No original: "par composition, on désigne la formation d'une unité sémantique à partir d'éléments susceptibles d'avoir par eux-mêmes une autonomie dans la langue.".

8 De acordo com Gross (1996, p. 5), Benveniste (1967) introduziu o termo synapsie, que pode ser definido como uma unidade de significação composta de vários morfemas lexicais; Martinet (1965) empregou o termo synthème, concebido como uma sequência formada por vários monumentos lexicais funcionando como uma unidade sintática mínima; Pottier (1987) usa o termo lexie composée, um conjunto que compreende várias palavras integradas, e Darmesteter (1874) trata de compostos que se opõem aos juxtaposés. 
de Gross (1996, p. 7, tradução nossa), "as palavras derivadas são sempre soldadas, as palavras polilexicais (ou complexas) podem ser soldadas (ultrapassar, e então, do ponto de vista informático, podem ser equiparadas a palavras simples), ou ter um separador (branco, apóstrofe, hífen)"9.

A partir dessa definição, observa-se que Gross (1996) tem uma concepção ampla do processo de composição, que engloba todas as estruturas fixas, soldadas ou não, ou seja, a posição do autor é a de que a composição é um fenômeno complexo, que envolve fatores heterogêneos. Além disso, o linguista francês esclarece que "não há outra razão senão a ortografia para considerar que estamos perante dois tipos de formação diferentes. O critério da soldadura não é, portanto, absoluto para separar os derivados dos compostos"10 (GROSS, 1996, p. 29, tradução nossa). Nesse contexto, cabe ressaltar que o termo alemão soudure é tomado pelo autor como um critério utilizado para definir uma palavra composta ${ }^{11}$.

A soldadura é o critério utilizado em alemão para definir uma palavra composta (Kompositum). A definição é, portanto, morfológica nesta língua: uma palavra composta é uma palavra soldada que funde graficamente duas ou mais outras, independentemente do carácter opaco ou não da significação ${ }^{12}$. (GROSS, 1996, p. 7, tradução nossa).

Radimský (2005, p. 10, tradução nossa), por sua vez, em uma tentativa de explorar o critério da soldadura ortográfica, esclarece que:

9 No original: "les mots dérivés sont toujours soudés, les mots polylexicaux (ou complexes) peuvent être soudés (outrepasser, et alors, du point de vue informatique, ils peuvent être assimilés à des mots simples), ou comporter un séparateur (blanc, apostrophe, trait d'union)...".

10 No original: "il n'y a pas de raison autre qu'orthographique de considérer qu'on est en présence de deux types de formations différents. Le critère de la soudure n'est donc pas absolu pour séparer les dérivés des composés.".

11 Observa-se que o autor reconhece a palavra composta como uma unidade semanticamente indecomponível e correspondente a uma única unidade significativa. Segundo Gross (1996, p. 4), "é chamada palavra composta uma palavra que contém dois, ou mais de dois, morfemas lexicais e que correspondem a uma unidade significativa: chou-fleur, malheureux, pomme de terre são palavras compostas". No original: "On appelle mot composé un mot contenant deux, ou plus de deux, morphèmes lexicaux et correspondant à une unité significative: chou-fleur, malheureux, pomme de terre sont des mots composés.".

12 No original: "La soudure est le critère utilisé en allemand pour définir un mot composé (Kompositum). La définition est donc morphologique dans cette langue: un mot compose est un mot soudé fusionnant graphiquement deux ou plusieurs autres, indépendamment du caractère opaque ou non de la signification.". 
De fato, A. Darmesteter (1894: 2-3) observa o critério da soldadura gráfica entre o que se oferece à mente em primeiro lugar; assim, as formações como licol, rouge-gorge e pomme de terre diferenciar-se-iam precisamente pelo seu grau de soldadura. Mas acrescenta também que uma soldadura formal («aglutinação») é um «puro acidente» na história da língua e constitui, por conseguinte, um critério artificial. Encontramos, portanto, no repertório dos compostos numerosas estruturas de tipo $\mathrm{N}+\mathrm{de}+\mathrm{N}$ (juge de paix, hôtel de ville), $\mathrm{N}+\mathrm{a}+\mathrm{N}$ (chambre à coucher, moulin à vent), $\mathrm{N}+\mathrm{em}+\mathrm{N}$ (arc-en-ciel, docteur en droit), etc. (Darmesteter A., 1894: 48) ${ }^{13}$.

De acordo com Radimský (2005, p. 10, tradução nossa), muitos linguistas não levam em conta o critério da soldadura gráfica, apenas tratam de compostos e não discutem a questão da estrutura ${ }^{14}$. Consequentemente, nota-se que o consenso sobre desconsiderar esse processo impede os linguistas de adotarem uma terminologia adequada para os compostos que se escrevem em várias palavras gráficas. Como já assinalado, a hipótese abordada neste trabalho fundamenta-se no ponto de vista de Gross (1996, p. 10, tradução nossa) para quem há "uma concepção bastante ampla de composição, englobando todas as estruturas fixas, soldadas ou não"15. Na sequência, discute-se a composição com ênfase no processo de justaposição e aglutinação, tomando-se como referência teóricos como Coutinho (1969), Carone (1986) e Kehdi (2007).

\section{Os nomes compostos: justaposição e aglutinação}

Tomando por base, inicialmente, o ponto de vista de Coutinho (1969, p. 175), a "composição é o processo de formação de palavras pela união de dois ou mais elementos vocabulares de significação própria ${ }^{16}$, que se combinam para representar uma ideia nova e única",

13 No original: "En fait, A. Darmesteter (1894: 2-3) note le critère de la soudure graphique parmi ceux qui s'offrent à l'esprit en premier; ainsi, les formations comme licol, rouge-gorge et pomme de terre se différencieraient précisément par leur degré de soudure. Mais il ajoute aussitot qu'une soudure formelle («agglutination») est un «pur accident» dans I 'histoire de la langue et constitue, par conséquent, un critère artificiel. Nous trouverons donc dans son répertoire des composés de nombreuses structures de type $\mathrm{N}+\mathrm{de}+\mathrm{N}$ (juge de paix, hôtel de ville), $\mathrm{N}+\mathrm{a}+\mathrm{N}$ (chambre à coucher, moulin à vent), N+en+N (arc-en-ciel, docteur en droit), etc. (Darmesteter A., 1894: 48).".

14 No original: "F. Gaudin et L. Guespin par exemple (2000: 283-2850) parlent de «composés» dans le cas des lexèmes du type $\mathrm{A}+\mathrm{N}, \mathrm{N}+\mathrm{A}, \mathrm{N}+\mathrm{à}+\mathrm{N}, \mathrm{N}+\mathrm{de}+\mathrm{N}, \mathrm{N}+\mathrm{N}, \mathrm{V}+\mathrm{N}, \mathrm{P}+\mathrm{N}$; ils ne disent toutefois rien sur d'autres structures, comme par exemple $\mathrm{N}+\mathrm{em}+\mathrm{N}$ (arc-en-ciel, mise em scène)». (RADIMSKÝ, 2005, p. 10). "F. Gaudin e L. Guespin, por exemplo (2000: 283-2850) falam de «compostos» no caso dos lexemas do tipo $A+N, N+A, N+a ̀+N, N+d e+N, N+N, V+N, P+N$; mas não dizem nada sobre outras estruturas, como por exemplo, $\mathrm{N}+e m+\mathrm{N}$ (arc-en-ciel, mise em scène)"..

15 No original: "une conception assez large de la composition englobant toutes les structures figées, soudées ou non".

16 É importante salientar que, de acordo com Kehdi (2007, p. 35), "na palavra composta, os elementos primitivos perdem a significação própria em benefício de um único conceito, novo, global". 
ou seja, a composição consiste na criação de uma palavra nova de significado único e constante, sempre e somente por meio de, no mínimo, dois radicais relacionados entre si. Trata-se da constituição de um todo e do modo pelo qual os elementos constituintes do todo se dispõem e se integram. Conforme ainda Coutinho (1969, p. 176), a formação de palavras por composição pode efetuar-se de três modos: por prefixação, por justaposição e por aglutinação. A posição desse autor acerca do processo de formação de palavras por justaposição e aglutinação ratifica o exposto:

Consiste a justaposição na junção de duas ou mais palavras, para formarem uma terceira, sem que haja alteração dos elementos componentes. Este processo de formação pode ser indicado pelo hífen ou pela simples aposição dos elementos formadores. Como quer que seja, nenhum deles é atingido em sua integridade material. À vista e ao ouvido são claramente distintos os elementos que entram nessa composição. Consiste a aglutinação na união íntima de duas ou mais palavras, para formarem uma terceira, o que se não dá sem prejuízo da integridade material de um dos elementos (alguns autores chamam a esta formação de palavras composição perfeita). Na aglutinação, o vocábulo composto fica subordinado a uma única acentuação tônica. (COUTINHO, 1969, p. 180).

Carone (1986), por sua vez, destaca que o papel da composição ${ }^{17}$ é apenas de gerador de palavras. A composição surge entre palavras que se encontram em sequência linear e, para tanto, é estritamente necessário que essas palavras estejam entrelaçadas por relações sintáticas ${ }^{18}$. No português, a palavra composta é resultante de uma sequência sintática formada por dois ou mais radicais, aglutinados ou justapostos, "o português não faz exceção: a palavra composta é resultante da cristalização de uma sequência sintática onde haja pelo menos dois radicais." (CARONE, 1986, p. 18).

Em outras palavras, Carone (1986, p. 37) define composição como o "procedimento pelo qual uma construção sintática se imobiliza, dando origem a uma unidade cristalizada". Para a autora, "realiza-se a composição com um mínimo de duas palavras portadoras de radical. Cada uma delas conserva sua identidade de vocábulo fonológico (justaposição); ou incorporam-se ambas em um só (aglutinação)" (CARONE, 1986, p. 37). É, assim, uma associação dos componentes das palavras compostas; trata-se de dois estágios de um mesmo processo, e não duas formas diferentes de composição (CARONE, 1986).

Outro ponto de vista que merece destaque é o delineado por Kehdi (2007, p. 35), segundo o qual a composição é um processo "de formação lexical que consiste na criação de

17 "Outro aspecto importante da composição é o fato de que as palavras que a formam estão relacionadas sintaticamente, por subordinação ou coordenação". (CARONE, 1986, p. 38).

18 Carone (1986, p. 101) parafraseando Hjelmslev conclui que "a sintaxe é a morfologia da frase e a morfologia é a sintaxe da palavra". 
palavras novas pela combinação de vocábulos já existentes". Também distingue dois tipos de composição: ocorre a justaposição quando não há redução de nenhum dos elementos mórficos das palavras que se agrupam, consideradas suas realidades fonológicas, isto é, "quando os termos associados conservam a sua individualidade", e tem-se a aglutinação quando na combinação das palavras que se agrupam há perda ou adaptação fonética de algum elemento, ou seja, "quando os vocábulos ligados se fundem num todo fonético, com um único acento, e o primeiro perde alguns elementos fonéticos" (KEHDI, 2007, p. 36).

Em síntese, pode-se concluir que está cristalizado como conceito de composição a junção de dois elementos identificáveis pelo falante em uma unidade nova de significado único. Discutido o conceito de composição, a estrutura do composto torna-se o foco do tópico que segue.

\section{Estrutura morfológica dos compostos indígenas}

Com relação à estrutura morfológica dos topônimos indígenas, no que se refere à incorporação de indigenismos na língua portuguesa, sabe-se que o processo foi tão efetivo que eles se tornaram produtivos, servindo de base para a formação de compostos e derivados. Neste artigo, são examinadas questões relacionadas à estrutura morfológica do elemento específico do sintagma toponímico (DICK, 1992), numa tentativa de sistematizar morfologicamente o processo de formação por composição.

No entanto, antes de discutir a questão da estrutura, torna-se necessário um olhar para a questão da estruturação dos topônimos de um modo geral, ou seja, a noção de sintagma toponímico cuja estrutura reúne dois elementos, o acidente geográfico e o topônimo, ambos intimamente ligados, uma vez que o sintagma toponímico é concebido como o resultado da relação binária entre o acidente geográfico ${ }^{19}$ (elemento genérico e determinado) e o topônimo (elemento específico e determinante) ${ }^{20}$. Para Dick (1992), ao se atribuir um nome próprio a um lugar, o topônimo liga-se ao acidente geográfico, o elemento genérico correspondente à entidade geográfica que receberá a denominação na condição de elemento específico, o topônimo propriamente dito, que particulariza a noção espacial. Ambos formam o sintagma toponímico, de forma justaposta ou aglutinada, conforme a natureza morfológica da língua que os inscreve.

190 acidente geográfico é o elemento genérico do sintagma toponímico (córrego, cabeceira, cachoeira, rio, ribeirão, serra etc.) e indica o referente nomeado.

200 elemento determinante é um termo que tem por função especificar o sentido de um outro termo, enquanto o determinado é um termo cujo sentido é especificado pelo anterior, sendo a ele subordinado. 
Desta forma, à luz da proposta de Dick (1992), a formação morfológica dos topônimos se dá de três maneiras: (i) elemento específico simples, definido por um só formante, acompanhado ou não por sufixos; (ii) elemento específico composto, estruturado a partir de elementos formadores de natureza diversa e (iii) elemento específico híbrido, formado por itens lexicais oriundos de diversas línguas. Nesse último caso, quanto à formação, os topônimos podem se configurar como simples híbridos e como compostos híbridos. Dick (1992 p. 14) esclarece que o topônimo híbrido, ou elemento específico híbrido, é "aquele designativo que recebe em sua configuração elementos linguísticos de diferentes procedências; a formação que se generalizou no país é a portuguesa + indígena ou a indígena + portuguesa".

A seguir, o Quadro 1 traz uma amostra de topônimos do corpus em estudo descrita a partir da proposta metodológica de Dick (1992).

Quadro 1. Análise de uma amostra de topônimos de base indígena na toponímia sulmato-grossense

\begin{tabular}{|c|c|c|c|}
\hline Topônimo & $\begin{array}{l}\text { Língua de } \\
\text { origem }\end{array}$ & Etimologia & $\begin{array}{l}\text { Estrutura } \\
\text { morfológica }\end{array}$ \\
\hline Apa & Tupi & $\begin{array}{l}\text { Apa: adj. desmoronante, desabado. } \\
\text { (SAMPAIO, 1987, p. 195) }\end{array}$ & $\begin{array}{l}\text { Simples (adj.) } \\
\text { 'Desmoronante' }\end{array}$ \\
\hline Pitangueira & $\begin{array}{l}\text { Tupi }+ \\
\text { Português }\end{array}$ & $\begin{array}{l}\text { Pitanga: adj. Vermelho, corado; fino delicado, } \\
\text { macio; a cútis fina; s. a criança, o menino. } \\
\text { É o nome da fruta ácida de pele delicada e } \\
\text { corada da Eugenia uniflora. (SAMPAIO, 1987, } \\
\text { p. 304) }\end{array}$ & $\begin{array}{l}\text { Simples Híbrido } \\
\text { (pitanga + -eira } \\
=\text { adj./subst. + } \\
\text { sufixo) } \\
\text { 'Pé de pitanga' }\end{array}$ \\
\hline Ipuí-pucu & Tupi & $\begin{array}{l}\text { Ipú: c. y-pú, a água surge ou borbulha; o } \\
\text { manancial, o olho d'água, fonte, minadouro } \\
\text { (SAMPAIO, 1987, p. 252); i: (ig) - s. água, rio, } \\
\text { líquido [...] (BUENO, 2008, p. 151). Pucu: adj. } \\
\text { Comprido; alto. (TIBIRIÇA, 1985, p. 150) }\end{array}$ & $\begin{array}{c}\text { Composto } \\
\text { (ipu }+\hat{i}+\text { pucu }= \\
\text { subst. }+ \text { subst. }+ \\
\text { adj.) } \\
\text { 'Manancial } \\
\text { comprido' }\end{array}$ \\
\hline $\begin{array}{l}\text { Jacu } \\
\text { Barreiro }\end{array}$ & $\begin{array}{l}\text { Tupi }+ \\
\text { Português }\end{array}$ & $\begin{array}{l}\text { Jacu: corr. Yacú, adj. Esperto, cuidadoso, } \\
\text { desconfiado, cauteloso. É o nome da ave do } \\
\text { gênero Penelope. Batista Caetano decompõe } \\
\text { o vocábulo em y-a-cú e o traduz o que come } \\
\text { grãos. (SAMPAIO, 1987, p. 264) }\end{array}$ & $\begin{array}{l}\text { Composto Híbrido } \\
\text { (jacu + barreiro } \\
\text { = subst./adj. + } \\
\text { subst.) } \\
\text { 'Jacu barreiro' }\end{array}$ \\
\hline
\end{tabular}

Fonte: Elaboração própria 
Por fim, busca-se acrescentar à proposta metodológica de Dick (1992) o exame do processo de transformação de topônimos polilexicais para monolexicais, com base no conceito de soldadura, nos termos de Gross (1996) e de Mejri (1997).

\section{Topônimos monolexicais de origem poliléxica}

Para analisar o grau de relevância de topônimos indígenas monolexicais de origem poliléxica e atestar a hipótese da soldadura como uma das características da toponímia da região estudada, busca-se apoio teórico-metodológico nas reflexões de Coutinho (1969, p. 181):

Muitas palavras alienígenas aparentam, em português, forma simples, quando na língua originária são compostas. Assim, temos compostos: [...] americanos, sobretudo da língua tupi-guarani: caroba (caaroba, mato amargo), capivara (caapiivara, comedor de capim), carioca (cari-oca, casa do branco), igara (ig-iara, dona d'água), socó (çoó-có, bicho que se arrima), Paquequer (pac-ker, dormida das pacas), Paraguai (paraguá-i, rio dos papagaios), Paraná (pará-nã, semelhante ao mar), Paraíba (pará-aiba, rio impraticável), Piraí (pirá-i, rio do peixe), Icarai (i-caraí, rio santo ou água santa).

Também se considera a posição de Monteiro (2002, p. 189) e sua advertência quanto a um equívoco "generalizado nas gramáticas portuguesas com a agravante de que a maioria dos exemplos indicados para a aglutinação (embora, fidalgo, freguês etc.) tem por base interpretações puramente diacrônicas".

Cumpre lembrar assim que muitos dos exemplos oferecidos para a composição por aglutinação não passam de vocábulos simples no estágio atual da língua. Para citar apenas um autor, lemos em Melo (1970) que são compostos perfeitos vocábulos como marechal, pedestal e vendaval. Pelo jeito, os chamados compostos perfeitos seriam justamente aqueles que já não são compostos, mas apenas vocábulos simples. (MONTEIRO, 2002, p. 189, grifo do autor).

Aplicando-se os pressupostos defendidos por Coutinho (1969) e por Monteiro (2002) aos de topônimos compostos de base indígena do corpus em questão, entende-se que determinados topônimos que, à primeira vista, denotam formações lexicais simples (monolexicais), mas na sua origem eram topônimos compostos (ou polilexicais), como ocorre em: «Cipó»: do tupi «lçá-pó» < içá 'galho' + pó 'mão' > correspondendo literalmente a "galho-mão, que é o mesmo que dizer galho apreensor que tem a propriedade de se prender, de se enlear, de atar. Alt. icepó, cepó, çapó, sipó". (SAMPAIO, 1928, p. 188). Trata-se de uma unidade lexical "simples" que na sua gênese era composta por dois itens lexicais indissociáveis, mas que, no estágio atual da língua, gerou uma única unidade de sentido, aglutinada com acomodação fonética (Içá + pó = subst. + subst.). Essa proposição é bem 
clara nos exemplos aqui examinados e caracterizados pelos processos de justaposição e aglutinação.

No entanto, para a abordagem da unidade toponímica composta com características de soldadura e, sobretudo, para atestar a importância de estudos acerca do caráter arbitrário da soldadura, subjacente a topônimos de base indígena, pauta-se mais uma vez em Gross (1996), com destaque para a parcialidade da fixidez e o alerta de que há graus de liberdade que oscilam entre sequências fixas e sequências que sofrem algum tipo de variação. Marques (2017, p. 26), pautando-se nas ideias de Gross (1996), esclarece que a fixidez, denominada, também, de cristalização, "diz respeito à soldadura entre os itens lexicais que integram a unidade fraseológica ou, neste caso, o fraseotopônimo".

Isso posto, ao considerar um topônimo composto como um caso de soldadura, neste trabalho busca-se aliar o conceito de unidades fraseológicas ao exame de topônimos, partindo, para tanto, da acepção de estruturas soldadas pelo uso da língua e formadas por combinações sintagmáticas que não podem ser improvisadas por serem sequências fixas como pode-se observar em: (Córrego) das Araras, (Passo) da Ariranha, (Serra) da Bodoquena, (Córrego) do Jacaré Grande, (Serra) de Maracaju, (Barra) do Morotim, (Lagoa) da Peroba, (Córrego) da Pindaiba, (Cabeceira) do Rio Amambai, (Cabeceira) do Rio Apa. Esses exemplos mostram que a segmentação de topônimos dessa natureza é impossível, confirmando, assim, a hipótese de soldadura.

O Quadro $2^{21}$, a seguir, apresenta uma amostra dos fenômenos linguísticos identificados no recorte de dados analisados, incluindo casos de topônimos candidatos à soldadura, com base na estrutura morfológica do topônimo.

21 No registro dos dados do quadro foram adotados os seguintes critérios: i) na coluna "topônimo" o componente indígena foi destacado em itálico; ii) na coluna "etimologia" foram registradas as informações etimológicas tão somente do componente indígena do topônimo. 
Quadro 2. Amostra de topônimos de estrutura composta na toponímia indígena sulmato-grossense

\begin{tabular}{|c|c|c|c|}
\hline \multicolumn{4}{|c|}{ MESORREGIÃO SUDOESTE/MATO GROSSO DO SUL } \\
\hline $\begin{array}{l}\text { Elemento } \\
\text { geográfico }\end{array}$ & Topônimo & Etimologia & $\begin{array}{l}\text { Estrutura } \\
\text { morfológica }\end{array}$ \\
\hline Córrego & Ita-Porã & $\begin{array}{l}\text { Itá: c. Y-tá, o que é duro, a pedra, o penedo, } \\
\text { a rocha, o seixo, o metal em geral, o ferro } \\
\text { (SAMPAIO, 1987, p. 254). Porã: adj. Bonito, } \\
\text { belo, formoso. (BUENO, 2008, p. 285). }\end{array}$ & $\begin{array}{c}\text { Composto } \\
\text { (ita + porã = subst. } \\
+ \text { adj.) } \\
\text { 'Pedra bonita' }\end{array}$ \\
\hline Córrego & Ponta Porã & $\begin{array}{l}\text { Porã: adj. Bonito, belo, formoso. (BUENO, } \\
\text { 2008, p. 285). }\end{array}$ & $\begin{array}{l}\text { Composto híbrido } \\
\text { (ponta + porã = } \\
\text { subst. + adj.) 'Ponta } \\
\text { bonita' }\end{array}$ \\
\hline Córrego & $\begin{array}{l}\text { Água da } \\
\text { Tapera }\end{array}$ & $\begin{array}{l}\text { Tapéra: corr. tab-éra, a aldeia extinta, a } \\
\text { ruína, lugar onde existiu uma povoação. } \\
\text { Alt. Taguéra. V. Taba (SAMPAIO, 1987, } \\
\text { p. 322). }\end{array}$ & $\begin{array}{c}\text { Composto híbrido } \\
\text { com soldadura } \\
\text { (água + da + tapera } \\
\text { = subst. + prep. + } \\
\text { subst.) } \\
\text { 'Água da aldeia } \\
\text { extinta' }\end{array}$ \\
\hline Riacho & Taquaruçu & $\begin{array}{l}\text { Taquaruçú: c. taquar-uçú, a cana grande, } \\
\text { a taquara grossa, bambu (SAMPAIO, 1987, } \\
\text { p. 325). Açú: adj. Grande, considerável. Alt. } \\
\text { oçú, uçú, guaçú (SAMPAIO, 1987, p. 191). }\end{array}$ & $\begin{array}{c}\text { Composto } \\
\text { aglutinado } \\
\text { (taquar }(a)+\text { uçu }= \\
\text { subst. + adj.) } \\
\text { 'Taquara grande' }\end{array}$ \\
\hline Cabeceira & Catingueiro & $\begin{array}{l}\text { Catinga: c. caá-tinga, o mato branco, } \\
\text { alvacento. Pode o vocábulo proceder } \\
\text { ainda de caá-t-enga, o mato ralo, que deixa } \\
\text { vácuos de permeio, isto é, o mato aberto } \\
\text { (SAMPAIO, 1987, p. 220). }\end{array}$ & $\begin{array}{c}\text { Composto } \\
\text { aglutinado híbrido } \\
\text { (ca (a) + ting (u) (a) } \\
+ \text {-eiro = subst. + } \\
\text { adj. + sufixo) 'Mato } \\
\text { branco' }\end{array}$ \\
\hline Cabeceira & Iguatemi, do & $\begin{array}{l}\text { Iguá: corr. Y-guá, o seio d'água, o mesmo } \\
\text { que igoá (SAMPAIO, 1987, p. 248). Tẽmĩ: } \\
\text { es particípio passivo de presente, la qual } \\
\text { particula junta a lo fixo del verbo, es lo } \\
\text { mismo que illud quod facio (MONTOYA, } \\
\text { 1876, p. } 377 \text { ). De acordo com Sampaio } \\
\text { (1987, p. 110) - do particípio passado } \\
\text { substantivo - este particípio se forma com } \\
\text { os prefixos: tembi ou temi, rembi ou remi, } \\
\text { sembi ou semi, gembi ou gemi, segundo a } \\
\text { gama dos temas. }\end{array}$ & $\begin{array}{c}\text { Composto } \\
\text { Justaposto com } \\
\text { soldadura } \\
\text { (do + igua + temi } \\
\text { = prep. + subst. } \\
+ \text { subst.) 'O seio } \\
\text { d'água' }\end{array}$ \\
\hline
\end{tabular}




\begin{tabular}{|c|c|c|c|}
\hline Córrego & Itaquiraí & $\begin{array}{l}\text { Itaquera: s.f. se tomar itá, pedra; coera, } \\
\text { cuera, goera como indicante aquilo que já } \\
\text { foi e não o é mais, itaquera será a pedreira } \\
\text { abandonada. Se tornarmos cuera como } \\
\text { sufixo do plural, muito usado no guarani, } \\
\text { será então pedreira, pedras (BUENO, 2008, } \\
\text { p. 173). Queraí: v. dormir mal. Forma } \\
\text { completa: queray-ba de quer, dormir, ayba, } \\
\text { ruim (BUENO, 2008, p. 298). }\end{array}$ & $\begin{array}{c}\text { Composto } \\
\text { aglutinado com } \\
\text { acomodação } \\
\text { fonética } \\
\text { (ita + [quer + ayba] } \\
\text { => ita + quir }(a)+(i) \\
\text { = subst. + verbo + } \\
\text { adj.) } \\
\text { 'A pedra ruim de } \\
\text { dormir' }\end{array}$ \\
\hline Córrego & Caarapó & $\begin{array}{l}\text { Caá: s., a folha, a planta, a erva, o vegetal } \\
\text { em geral; a árvore, o mato, o monte; o mate. } \\
\text { Alt. Cá (SAMPAIO, 1928, p. 173). Rapó: V. } \\
\text { hapó (TIBIRIÇÁ 1989, p. 151). Hapó: s. raiz; } \\
\text { tubérculo (TIBIRIÇÁ, 1989, p. 62). }\end{array}$ & $\begin{array}{c}\text { Composto } \\
\text { justaposto } \\
\text { (caa + rapó = subst. } \\
\text { + subst.) } \\
\text { 'Mato raiz' }\end{array}$ \\
\hline Córrego & landejara & $\begin{array}{l}\text { landeyara: s. Nosso Senhor de landé (de } \\
\text { nós, nosso) - Yara, Senhor (BUENO, 2008, } \\
\text { p. 151). }\end{array}$ & $\begin{array}{c}\text { Composto } \\
\text { justaposto com } \\
\text { acomodação } \\
\text { fonética (iande + } \\
\text { jara = pron./subst. + } \\
\text { subst.) } \\
\text { 'Nosso Senhor' }\end{array}$ \\
\hline Cabeceira & Tatuí, do & $\begin{array}{l}\text { Tatu: c. ta-tú, o casco encorpado, ou grosso, } \\
\text { couraça (SAMPAIO, 1928, p. 321); i: s. água, } \\
\text { rio, líquido [...] (BUENO, 2008, p. 151). }\end{array}$ & $\begin{array}{c}\text { Composto } \\
\text { justaposto com } \\
\text { soldadura } \\
\text { (do + tatu + í = prep. } \\
\text { + subst. + subst.) } \\
\text { 'Rio do tatu' }\end{array}$ \\
\hline Rio & Laranjaí & $\begin{array}{l}\text { i: (ig) - s. água, rio, líquido [...] (BUENO, 2008, } \\
\text { p. 151). }\end{array}$ & $\begin{array}{c}\text { Composto } \\
\text { justaposto híbrido } \\
\text { (laranja }+ \text { í = subst. } \\
\text { + subst.) 'Rio da } \\
\text { laranja' }\end{array}$ \\
\hline
\end{tabular}




\begin{tabular}{|c|c|c|c|}
\hline Cabeceira & $\begin{array}{c}\text { Rio Maracaí, } \\
\text { do }\end{array}$ & $\begin{array}{l}\text { Maraca: c. marã-acã, a cabeça de } \\
\text { fingimento; instrumento feito de um } \\
\text { cabaço do tamanho da cabeça humana } \\
\text { com orelha, cabelos, olhos, narinas e } \\
\text { boca, estribado numa flecha como sobre } \\
\text { pescoço. Depois da conquista, o maracá } \\
\text { ficou servindo para denominar o chocalho } \\
\text { (SAMPAIO, 1928, p. 261). i: (ig) - s. água, rio, } \\
\text { líquido [...] (BUENO, 2008, p. 151). }\end{array}$ & $\begin{array}{l}\text { Composto híbrido } \\
\text { com soldadura } \\
\text { marcado pelo } \\
\text { processo de } \\
\text { toponimização }{ }^{22} \\
\text { (do + rio + maraca + } \\
\text { í prep. + subst. + } \\
\text { subst. + subst.) } \\
\text { 'do rio maracá rio' }\end{array}$ \\
\hline
\end{tabular}

Fonte: Elaboração própria

Considerando o raciocínio adotado na descrição dos topônimos elencados no Quadro 2, o tópico seguinte é destinado à apresentação e análise dos dados examinados para este estudo. De um ponto de vista metodológico, como já pontuado, adota-se uma postura sincrônica com relação a alguns aspectos morfológicos e, em um segundo momento, utiliza-se a diacronia para explicação de caráter etimológico, dado necessário e esclarecedor como argumento de sustentação da proposta em discussão.

\section{Apresentação dos resultados}

Como já assinalado anteriormente, para este trabalho, foi examinada uma amostra de 832 topônimos. Dentre eles, aplicando-se a metodologia adotada e o referencial teórico tomado como parâmetro, 454 se configuram como compostos, com as seguintes distribuições: 195 justapostos e, desses, 8 com soldadura; 109 compostos aglutinados, sendo 3 formados por soldadura; 110 compostos híbridos, incluindo 8 por soldadura, e 40 compostos por hifenização e/ou espaço em branco.

Acredita-se que essas ocorrências podem elucidar a estrutura de muitos topônimos indígenas que estão em análise. Nessa amostra, também foram identificados, mas não considerados aqui, 272 topônimos de estrutura simples; 32 simples híbridos e, entre eles, 6 com soldadura. Até o estágio atual do estudo, não foi identificada a estrutura morfológica de 74 topônimos compostos, em virtude de carência de fontes confiáveis com informações etimológicas de unidades lexicais de origem indígena.

Na sequência, no Quadro 3, apresenta-se uma amostra de topônimos que evidenciam cinco possibilidades de exame da estrutura composta: composto, composto híbrido, composto justaposto, composto aglutinado e composto por soldadura.

22 De acordo com Dick (1992, p. 64), "os acidentes geográficos incorporam também o sentido de topônimo, dando origem a novas construções toponomásticas". 
Quadro 3. Topônimos indígenas de estrutura composta na toponímia sul-matogrossense

\begin{tabular}{|l|l|l|}
\hline Elemento geográfico & Topônimo & Estrutura morfológica \\
\hline Rio & Anhanduí & Composto justaposto \\
\hline Córrego & Caverá & Composto aglutinado \\
\hline Córrego & Boÿaguá & Composto aglutinado híbrido \\
\hline Córrego & Caarapozinho & Composto justaposto híbrido \\
\hline Cabeceira & Jaguari, do & Composto justaposto (com soldadura) \\
\hline
\end{tabular}

Fonte: Elaboração própria

Na sequência, apresenta-se o detalhamento do processo de formação evidenciado na estrutura morfológica dos topônimos apresentados no quadro 3:

(01) Anhanduí: composto por justaposição: prefixo A + substantivo Nhandú (ema/avestruz) + substantivo í (rio - marca do elemento água) = o rio das emas.

(02) Caverá: composto por aglutinação: substantivo Caá (folha/mato) + adjetivo verá/berá (brilhante) $=$ mato brilhante.

(03) Boÿaguá: composto por aglutinação e hibridismo: substantivo Boy (cobra/serpente) + substantivo água $=$ cobra d'água .

(04) Caarapozinho: composto por justaposição e hibridismo: substantivo Caá (folha/mato) + substantivo rapó (raiz) + sufixo -zinho = raizinha do mato.

(05) Jaguari: Composto por justaposição com soldadura: preposição do (como marca de soldadura) + substantivo jagua(r) (onça) + substantivo i (rio - marca do elemento água) = o rio da onça.

A Tabela 1, a seguir, confirma, a princípio, que a composição é o processo mais produtivo no corpus e, consequentemente, a justaposição e a aglutinação são os mecanismos mais recorrentes na amostra examinada, resultando que a hipótese de soldadura foi pouco significativa no recorte de dados analisado. 
Tabela 1. Produtividade dos topônimos indígenas examinados conforme a estrutura morfológica

\begin{tabular}{l|c|c}
\hline \multicolumn{1}{c}{ MESORREGIÃo SUDOESTE/MATO GROSSO DO SUL } \\
\hline \multicolumn{2}{c}{ Estrutura Morfológica } & Ocorrências \\
\cline { 2 - 3 } & Números absolutos & $\%$ \\
\hline Composto & 40 & $4,80 \%$ \\
\hline Composto híbrido & 102 & $12,25 \%$ \\
\hline Composto híbrido (com soldadura) 23 & 8 & $0,96 \%$ \\
\hline Composto aglutinado & 96 & $11,53 \%$ \\
\hline Composto aglutinado híbrido & 9 & $1,08 \%$ \\
\hline Composto aglutinado (com soldadura) & 3 & $0,36 \%$ \\
\hline Composto aglutinado (com acomodação fonética) & 1 & $0,12 \%$ \\
\hline Composto justaposto & 101 & $12,13 \%$ \\
\hline Composto justaposto (com acomodação fonética) & 75 & $9,01 \%$ \\
\hline Composto justaposto (com soldadura) & 8 & $0,96 \%$ \\
\hline Composto justaposto híbrido & 11 & $1,32 \%$ \\
\hline Não identificada & 74 & $8,89 \%$ \\
\hline Simples & 272 & $32,69 \%$ \\
\hline Simples híbrido & 26 & $3,12 \%$ \\
\hline Simples híbrido (com soldadura) & 632 & $0,72 \%$ \\
\hline Total & & $100 \%$ \\
\hline
\end{tabular}

Fonte: Elaboração própria

Os resultados da análise do recorte de dados aqui discutidos evidenciam um número significativo de topônimos polilexicais que, sincronicamente, são cristalizados como topônimos monolexicais. Todavia, são pouco representativas as unidades lexicais compostas, cujos elementos de origem foram unidos pelo processo de soldadura; acredita-

23 Das oito ocorrências encontradas e classificadas como compostos híbridos com soldadura, seis são marcados pelo processo de toponimização. 
se que topônimos compostos que nomeiam acidentes humanos e que se configuram como sequências polilexicais cristalizadas sejam mais produtivos ${ }^{24}$ nesse particular. No entanto, apesar desses números, o corpus em que se baseia este estudo fornece uma amostra da riqueza de que se reveste a tendência do processo de composição em termos de nomeação de acidentes físicos da área rural da mesorregião Sudoeste do Mato Grosso do Sul, em se tratando de topônimos indígenas.

A análise dos topônimos quanto à origem linguística evidenciou que o Tupi é, sem dúvida, na tradição brasileira, um depósito de raízes lexicais que serve, neste caso, para formar, topônimos. A Tabela 2, a seguir, reúne as informações relativas à língua de origem dos topônimos aqui examinados e destaca que 56,73\% das ocorrências são de origem Tupi; 7,81\% Guarani; 6,61\% Tupi e Português; 6,25\% Português e Guarani; 2,28\% Tupi e Guarani e 2,16\% Português e Tupi, citando-se apenas as ocorrências mais produtivas.

Tabela 2. Produtividade dos topônimos indígenas analisados segundo a língua de origem

\begin{tabular}{l|c|c}
\hline \multicolumn{1}{c|}{ Língua de origem } & \multicolumn{2}{c}{ Ocorrências } \\
\hline Tupi & 472 & $56,73 \%$ \\
\hline Não identificada & 109 & $13,10 \%$ \\
\hline Guarani & 65 & $7,81 \%$ \\
\hline Tupi + Português & 55 & $6,61 \%$ \\
\hline Português + Guarani & 52 & $6,25 \%$ \\
\hline Tupi + Guarani & 19 & $2,28 \%$ \\
\hline Português + Tupi & 18 & $2,16 \%$ \\
\hline Guarani + Tupi & 8 & $0,96 \%$ \\
\hline Tupi + Não Identificada & 8 & $0,96 \%$ \\
\hline Guaikuru/Tapuia & 4 & $0,48 \%$ \\
\hline Guarani + Português & 3 & $0,36 \%$ \\
\hline Não Identificada + Português & 3 & $0,36 \%$ \\
\hline Guarani/Paraguai & 3 & $0,36 \%$ \\
\hline Guarani + Não Identificada & 2 & $0,24 \%$ \\
\hline
\end{tabular}

24 Essa hipótese poderá ser analisada em uma nova proposta de estudo. 


\begin{tabular}{l|c|c}
\hline Português + Não Identificada & 2 & $0,24 \%$ \\
\hline Grego + Guarani & 2 & $0,24 \%$ \\
\hline Árabe + Português + Guarani & 1 & $0,12 \%$ \\
\hline Árabe + Guarani & 1 & $0,12 \%$ \\
\hline Espanhol + Guarani & 1 & $0,12 \%$ \\
\hline Quíchua & 1 & $0,12 \%$ \\
\hline Terena/Tapuia & 1 & $0,12 \%$ \\
\hline Tupi + Guarani + Português & 1 & $0,12 \%$ \\
\hline Tupi + Espanhol & 832 & $0,12 \%$ \\
\hline Total & & $100 \%$ \\
\hline
\end{tabular}

Fonte: Elaboração própria

O resultado espelhado na tabela confirma o observado por Sampaio (1928, p. 33-34):

Não há quem desconheça a predominância do tupi em nossas denominações geográficas. As nossas montanhas, os nossos rios, as cidades, os povoados, trazem geralmente nomes bárbaros que o gentio, dominador outrora, Ihes aplicou, que os conquistadores respeitaram e que hoje são de todos preferidos, pois, não raro, substituem-se nomes portugueses de antigas localidades por outros de procedência indígena, às vezes lembrados ou compostos na ocasião, às vezes restaurados pelos amadores de coisas velhas e tradicionais.

Em síntese, conclui-se que o Tupi é patrimônio dos brasileiros e está sempre vivo nos nomes de acidentes geográficos e nas palavras que usamos para nomear coisas ou objetos comuns, por isso a herança do Tupi no léxico do português brasileiro é tão marcante. Os dados examinados para este estudo evidenciaram marcas significativas da herança indígena no cenário toponímico do estado de Mato Grosso do Sul.

\section{Algumas considerações finais}

Este artigo teve como foco os processos de formação de palavras por composição, evidenciados na estrutura morfológica de topônimos de base indígena. Resumindo, conclui-se que decompor o item lexical em função toponímica pelos seus elementos aglutinados e ter em vista que as denominações são em geral de uma realidade descritiva configuram-se como um caminho propício para a interpretação de topônimos indígenas. 
Este trabalho considera, sobretudo, o fato de os indígenas terem por prática nomear o local por meio de traços precisos, de forma instintiva e descritiva. Porém, é indiscutível que muitas denominações foram adulteradas e/ou aportuguesadas com o intuito de abafar as vozes dos aborígenes, algumas substituições foram, especialmente, ordenadas para dissimular a origem indígena de muitos topônimos.

O corpus em que se baseia este estudo fornece uma amostra da riqueza de que se reveste a língua portuguesa e as línguas indígenas do Brasil, em termos de nomeação de acidentes físicos que, por sua vez, evidenciam um número representativo de topônimos "simples" de origem composta. Além disso, os topônimos examinados deixam transparecer aspectos da relação do homem com seu entorno físico e cultural no ato de nomeação, neste caso, no processo de construções lexicais complexas.

A discussão das tendências da composição e do processo de soldadura, objetivo principal deste estudo, demonstrou que, sem sombra de dúvidas, o processo de formação mais recorrente nos topônimos indígenas é o da composição, mais especificamente, a composição por justaposição, responsável pela formação de 23,42\% (195) dos topônimos analisados. Desse montante, 36,53\% (304) dos topônimos foram considerados unidades lexicais simples de origem composta, classificados sobretudo como compostos, e $3 \%$ (25) dos dados foram categorizados pelo processo de soldadura.

Desta forma, conclui-se que a recorrência do processo de formação por composição se deve ao fato de o Tupi e o Guarani, línguas de maior recorrência nos dados analisados, serem línguas incorporantes. Tem-se, também, por certo que foram o Tupi e o Guarani antigos que mais contribuíram para o enriquecimento do vocabulário e da toponímia em estudo. Logo, o fenômeno do hibridismo evidenciado na toponímia em análise resulta tanto do contato entre os indígenas e os portugueses quanto da influência da colonização na alteração de itens lexicais de origem indígena e no surgimento de novas palavras, o que interferiu no processo de denominação dos lugares.

Em síntese, os dados confirmam que a toponímia brasileira foi profundamente marcada pela influência indígena. Embora este texto, dada a sua amplitude e considerando os seus objetivos, não tenha contemplado todos os enfoques teóricos possíveis e nem tenha tido o propósito de esgotar o assunto, forneceu resultados que poderão subsidiar novas reflexões sobre a temática tratada. Assim, a discussão aqui apresentada é produto de uma interpretação do assunto à luz dos enfoques teóricos adotados e tem a expectativa de que, além de ter avançado no exame da temática, possa suscitar novas discussões.

\section{Agradecimentos}

As autoras Camila André do Nascimento da Silva e Aparecida Negri Isquerdo agradecem, respectivamente, à CAPES e ao CNPq pelo financiamento das suas pesquisas. 


\section{REFERÊNCIAS}

ATEMS - Atlas Toponímico de Mato Grosso do Sul. Sistema de Dados. Campo Grande: UFMS, 2019 (acesso restrito).

BASILIO, M. Formação de palavras no português do Brasil. 4. ed. São Paulo: Contexto, 2013.

BUENO, S. Vocabulário Tupi-Guarani Português. 7. ed. São Paulo: Vida Livros, 2008.

CARONE, F. de B. Morfossintaxe. São Paulo: Ática, 1986.

COUTINHO, I. de L. Pontos de Gramática Histórica. 6. ed. Rio de Janeiro: Livraria Acadêmica, 1969.

DAUZAT, A. Les noms de lieux: origine et évolution, villes et villages, pays, cours d'eau, montagnes, lieux-dits. Paris: Librairie Delagrave, 1947.

DICK, M. V. de P. A. A motivação toponímica e a realidade brasileira. São Paulo: Edições Arquivo do Estado, 1990.

DICK, M. V. de P. A. Toponímia e Antroponímia no Brasil. Coletânea de Estudos. São Paulo: Serviço de Artes Gráficas/FFLCH/USP, 1992.

GROSS, G. Les expressions figées en français. Noms composés et autres locutions. Paris: Editions Ophrys, 1996.

KEHDI, V. Formação de palavras em português. 4. ed. São Paulo: Ática, 2007.

MARQUES, E. A. Fraseotopônimos: estabelecendo diálogos entre a fraseologia e a toponímia. Revista Guavira, Três Lagoas/MS, n. 25, p. 23-33, jul./dez. 2017. Disponível em: http://websensors.net.br/seer/index.php/guavira/article/view/589/435. Acesso em: 09 abr. 2020.

MEJRI, S. Le figement lexical, descriptions linguistiques structuration sémantique. Tunis: Publications de La Faculté des Lettres, Université de La Manouba, 1997.

MONTEIRO, J. L. Morfologia Portuguesa. 4. ed. revista e ampliada. Campinas: Pontes, 2002. 
MONTOYA, A. R. de. Gramatica y diccionarios (arte, vocabulario y tesoro) de la lengua tupi ó guarani. Vienna: Faesy y Frick; Paris: Maisonneuve y Cia, 1876.

RADIMSKÝ, J. Les composés italiens actuels. 2005. Thèse (Doctorat en Philologie) - Faculté des Lettres, Institut D'etudes Romanes, Université Charles, Prague, 2005. Disponível em: https://is.cuni.cz/webapps/zzp/download/150020815. Acesso em: 16 ago. 2019.

RODRIGUES, A. D.'I. A composição em Tupi. Separata de Logos, ano VI, n. 14. Curitiba, p. 1-8, 1951. Disponível em: http://biblio.wdfiles.com/local--files/rodrigues-1951-composicao/ rodrigues_1951_composicao.pdf. Acesso em: 20 jun. 2019.

SAMPAIO, T. O tupi na geografia nacional. 5. ed. São Paulo: Editora Nacional, 1987.

SAMPAIO, T. O tupi na geografia nacional. 3. ed. Bahia: Secção Graphica da escola de Aprendizes Artificies, 1928.

TIBIRIÇÁ, L. C. Dicionário Guarani Português. São Paulo: Traço Editora, 1989.

TIBIRIÇÁ, L. C. Dicionários de Topônimos de Origem Tupi: significado dos nomes geográficos de origem tupi. São Paulo: Traço Editora, 1985. 